\title{
BMJ Open Primary care staff's willingness to participate in compassionate community network and palliative care and the barriers they face: a mixed methods study
}

\author{
Hsiao-Ting Chang (D) ,1,2 Ming-Hwai Lin,, ${ }^{1,2}$ Wen-Hua Kuo, ${ }^{3}$ Chun-Ku Chen, ${ }^{2,4}$ \\ Tzeng-Ji Chen, ${ }^{1,5}$ Shinn-Jang Hwang ${ }^{1,2}$
}

To cite: Chang $\mathrm{H}-\mathrm{T}$, Lin $\mathrm{M}-\mathrm{H}$, Kuo W-H, et al. Primary care staff's willingness to participate in compassionate community network and palliative care and the barriers they face: a mixed methods study. BMJ Open 2021;11:e046961. doi:10.1136/ bmjopen-2020-046961

- Prepublication history for this paper is available online. To view these files, please visit the journal online (http://dx.doi. org/10.1136/bmjopen-2020046961).

Received 14 November 2020 Accepted 05 September 2021

Check for updates

(C) Author(s) (or their employer(s)) 2021. Re-use permitted under CC BY-NC. No commercial re-use. See rights and permissions. Published by BMJ.

For numbered affiliations see end of article.

Correspondence to

Dr Hsiao-Ting Chang;

htchang.tw@gmail.com

\section{ABSTRACT}

Objectives Compassionate community models, successfully applied in several Western countries, have not been extensively promoted in Asian countries. This study explored primary care staff's willingness to participate and factors associated with their participations in compassionate community education and network, palliative care education, providing palliative care and the barriers they faced.

Methods Adopting a mixed quantitative-qualitative design, primary care staffs in Beitou and Shilin districts in Taiwan, including physicians, nurses, pharmacists and administrative staff aged $\geq 20$ years who had worked in a clinic for more than 2 months, were recruited. A questionnaire survey was conducted to explore their willingness to participate in compassionate community education and networks and palliative care education and care provision. Logistic regression was used to evaluate factors associated with their willingness, and qualitative perceptions were evaluated by open questions.

Results About half of the respondents were willing to participate in compassionate community education and network and palliative care education, but only 19.5\% were willing to provide palliative care. Compared with other staff, primary care nurses showed significantly more willingness to participate in compassionate community education and network and palliative care education and to provide palliative care. However, physicians were significantly not willing to participate in any of the three services apart from providing care. Capability, administrative and manpower concerns, time, age and motivation were the main barriers.

Conclusions To encourage primary care staff to participate more in compassionate community education and network and palliative care education and to provide palliative care, policymakers should pay more attention towards removing the barriers to their engagement.

\section{INTRODUCTION}

The compassionate community model was proposed by Kellehear in $1998 .^{1}$ It emphasised that communities could support those
Strengths and limitations of this study

- This is the first study in Asia to explore primary care staffs' willingness to participate in compassionate community education and network and palliative care education and provide palliative care, using both collected quantitative and qualitative data to improve validity of results.

- The respondents included the main staff in primary care settings in Taiwan, including physicians and nurses; given the acceptable response rate, the results could have acceptable representativeness for the staffs' willingness.

- Because of the cross-sectional study design, we were unable to show the causal relationship between the factors associated with the respondents' willingness to participate in these programmes.

- The study questionnaire used four open questions for respondents to express their reasons for participation (or the lack of it), but in-depth interviews are necessary, in further research, for a more detailed interpretation of these answers.

living with life-threatening or life-limiting illnesses, ageing, long-term caregiving, grief and bereavement. ${ }^{2}$ Through a public health approach, education and information are provided to facilitate policymaking and further empowerment of the community, including developing volunteers in support networks and social spaces and providing professional education and services to assist those in need. ${ }^{1-4}$

Since the compassionate community model was introduced, many Western countries have successfully applied this model. For example, in Scotland, Children's Hospice Association Scotland, Strathcarron Hospice and St Andrew's Hospice have set up health-promoting palliative care (HPPC) programmes to promote community 
engagement since 2007. ${ }^{4}$ Meanwhile, Abel et at established compassionate community network (CCN) at Weston-super-Mare in the UK to support those wanting to die at home. Greene and colleagues found that active engagement of community network facilitators could relieve caregivers' fatigue, provide support and decrease their resentment. ${ }^{6}$ In Barcelona, the 'Vic, caring city' Project was established successfully ${ }^{7}$ and the 'All with You' model in Spain and Latin America. ${ }^{8}$ Pallium Canada is another successful compassionate community model. ${ }^{9}$ In Asia, Taiwan has been working to prevent suffering ${ }^{10}$ by integrating palliative care (PC) services ${ }^{11} 12$ to encourage community engagement that improves the overall quality of life of people and to support terminal patients at home. However, PC and support are mainly provided by professional teams in hospitals, and there is a lack of volunteers for this in the community.

To encourage community engagement, it is important to disseminate knowledge about a compassionate community, specifically what kind of supports could be provided by such a network, as well as some basic PC education (PCE) and skills for caregivers to support those in need. To the best of our knowledge, no previous study has focused on factors associated with primary care staff members' willingness to participate in a CCN or compassionate community education (CCE), although some have considered professionals' willingness to provide PC. A previous study showed that PCE is independently associated with the agreement on general practitioners' (GPs) roles in PC. ${ }^{13}$ Another study found that community physicians' PC experience and beliefs, rather than their knowledge, were related to their willingness to provide PC for patients with terminal cancer ${ }^{14}$ Further, another study found that PC knowledge was associated with community nurses' willingness to provide PC in rural communities. ${ }^{15}$ Additionally, community pharmacists could play roles in community PC through medication reviews to improve patients' medication management and decrease errors, and their involvement could also improve medicationrelated knowledge and skills of care team members. ${ }^{16} 17$ Due to the primary care staff being close to the community members, this study aimed to explore, through a questionnaire survey, their willingness, along with the barriers, to their participation in CCE, PCE and CCN as volunteers and to provide PC and the associated factors. Furthermore, learning about the barriers to these issues, it was assumed, would help create and implement preventive or ameliorative measures to facilitate the staff's engagement in these programmes.

\section{METHODS}

\section{Study design, setting and participants}

This study was a cross-sectional survey, conducted in the Beitou and Shilin districts (Taipei City, Taiwan) by telephone survey, from January to June 2020, by a research assistant trained to conduct this survey and answer interviewees' questions by standard procedure. The inclusion criteria were that the staff in primary care clinics in the aforementioned districts had to be 20 years or older and working in the clinics for more than 2 months. At the end of August 2018, there were 217 primary care clinics in these districts; one key staff in each clinic was recruited.

\section{Measurements}

A semistructured questionnaire was developed to evaluate the staff's willingness to participate in CCE, CCN and PCE and provide PC. Validity of the questionnaire was assessed by an expert panel of two medical doctors and two nurses who had at least 10 years of experience in clinical care and PC. The questionnaire was then pilottested by 20 primary care clinic staff members, and testretest reliability was checked after a week and found to be ranging from 0.70 to 1.0 . The questionnaire contained the characteristics of the primary clinics (number of staff and services provided), personal demographical characteristics of participants (age, sex, marital status, education level, religious belief, type of profession, position in the primary care clinic, monthly income and CCE and PCE in the last 3 years), questions regarding the willingness to participate in CCE, CCN and PCE and to provide PC with yes/no answers and an open question to answer as the third component. We explained CCE, CCN, PCE and PC to participants: we will provide a 30-minute class to talk about what is compassionate community, how to establish CCN in Beitou and Shilin districts and supports and services that could be provided to people in the community. For CCN, we set up a coordination office in the department of family medicine, Taipei Veterans General Hospital, and told participants that they could join the network as volunteers. For PCE, we will provide classes that explained PC, the Hospice Palliative Care Act 2000, common symptoms of terminally ill patients and managements, how to support the people and their families, endof-life care and bereavement care. The participants were told they could provide support or professional care to those in need.

\section{Quantitative data analysis}

Quantitative data were analysed using IBM SPSS V.20.0. Descriptive statistics (number (n) and percentage (\%)) were used to analyse the categorical variables of participants' demographic and primary care clinics' characteristics. The age of participants was presented as mean and SD and categorised as 20-39, 40-59 and $\geq 60$ years. Logistic regression analyses adjusted for covariates, including participants' demographical characteristics, and experiences of receiving CCE and PCE in the past 3 years were used to analyse factors related to participants' willingness to participate in CCN and provide PC. A two-tailed $p$ value $<0.05$ was considered statistically significant. For questions on participants' willingness to participate in CCE, CCN and PCE and to provide PC, we presented the results by answers, number of participants and percentages. 
Table 1 Demographical characteristics of respondents (total $n=159$ )

\begin{tabular}{|c|c|c|}
\hline Demographical characteristics & $\mathbf{N}$ & $\%$ \\
\hline Age in years, (mean, SD) & 51.4 & 14.1 \\
\hline 20-39 & 33 & 20.8 \\
\hline $40-59$ & 75 & 47.2 \\
\hline$\geq 60$ & 51 & 32 \\
\hline \multicolumn{3}{|l|}{ Sex } \\
\hline Male & 67 & 42.1 \\
\hline Female & 92 & 57.9 \\
\hline \multicolumn{3}{|l|}{ Marital status } \\
\hline Married & 138 & 86.8 \\
\hline Single & 21 & 13.2 \\
\hline \multicolumn{3}{|l|}{ Education level } \\
\hline Below university & 19 & 6.3 \\
\hline University and above & 149 & 93.7 \\
\hline \multicolumn{3}{|l|}{ Religious belief } \\
\hline No & 11 & 6.9 \\
\hline Yes & 148 & 93.1 \\
\hline \multicolumn{3}{|l|}{ Profession } \\
\hline Physician & 79 & 49.7 \\
\hline Nurse & 46 & 28.9 \\
\hline Administrative staff & 32 & 20.1 \\
\hline Pharmacist & 2 & 1.3 \\
\hline \multicolumn{3}{|l|}{ Position in the clinic } \\
\hline Head & 81 & 50.9 \\
\hline Supervisor & 15 & 9.4 \\
\hline Main staff & 63 & 39.6 \\
\hline Current working years & 14.7 & 12.1 \\
\hline Total working years & 24.4 & 11.9 \\
\hline \multicolumn{3}{|l|}{ Monthly income (NTD) } \\
\hline$\leq 59999$ & 79 & 49.7 \\
\hline$\geq 60000$ & 79 & 49.7 \\
\hline $\begin{array}{l}\text { Heard about compassionate } \\
\text { community }\end{array}$ & 96 & 60.4 \\
\hline $\begin{array}{l}\text { Ever received compassionate } \\
\text { community education in the past } 3 \\
\text { years }\end{array}$ & 21 & 13.2 \\
\hline $\begin{array}{l}\text { Ever received palliative care education } \\
\text { in the past } 3 \text { years }\end{array}$ & 40 & 25.2 \\
\hline
\end{tabular}

NTD, New Taiwan Dollar.

\section{Qualitative data analysis}

Answers to the open questions about the willingness and barriers to participate in the aforementioned education and networks and provide PC were analysed using conventional content analysis. ${ }^{18-20}$ Participants were invited to respond to these questions, and their answers were transcripted. Due to their busy practice schedule and limited time granted for our interview, many of the interviewees' answers were too brief for a conventional coding approach. Therefore, categorical codes were developed for their willingness to attend CCE and PCE activities and to participate in CCN and provide PC services and the reasons for their concerns. H-TC established the preliminary codes, which were reviewed by W-HK and M-HL; post discussions on the rationale of coding, the coding lists were established and the adopted codes classified into categories. Disparities in coding were discussed and negotiated with C-KC, T-JC and S-JH to ensure analytical rigour.

\section{Ethics}

This study was approved by the institutional review board of Taipei Veterans General Hospital (2019-01-024AC). Verbal agreement to take the telephone survey was considered as consent to participate.

\section{Patient and public involvement}

Patients or members of the general public were not involved in the design or execution of this study.

\section{QUANTITATIVE RESULTS}

Response rate and characteristics of respondents and primary care clinics

The staff of 159 primary care clinics participated, and the response rate was $73.4 \%$. Tables 1 and 2 present the characteristics of the participants and the primary care clinics. The mean age of respondents was 51.4 ( $\mathrm{SD}=14.1$ years). The majority were women $(57.9 \%)$ and in the $40-59$ age group $(47.2 \%) ; 86.8 \%$ were married; $93.7 \%$ had an educational level of university or above; $93.1 \%$ had a religious belief; $79(49.7 \%)$ were physicians and $46(28.9 \%)$ nurses; $96(60.3 \%)$ were head or supervisor in the primary care clinics; $96(60.4 \%)$ had heard about compassionate community, and of them, $52(54.2 \%)$ were physicians, and 31 (32.3\%) were nurses; 21 (13.2\%) had ever received CCE in the past 3 years; and 40 (25.2\%) had never received PCE in the past 3 years (table 1). The median number of staff in the primary care clinics was six, with an IQR of 5.0. The services provided by these clinics were primary care $(95.6 \%)$, adults' preventive health

Table 2 Characteristics of primary care clinics (total $n=159$ )

\begin{tabular}{lrc}
\hline Characteristics & N & $\%$ \\
\hline Number of staff (median, IQR) & 6 & 5.0 \\
Services provided & 152 & \\
$\quad$ Primary care & 72 & 45.6 \\
Adults' preventive health services & 67 & 42.1 \\
Influenza vaccination & 41 & 25.8 \\
Older adults' preventive health services & 25 & 15.7 \\
Children's preventive health services & 22 & 13.8 \\
Compassionate community services & 9 & 5.7 \\
Palliative care & 4 & 2.5 \\
\hline Home healthcare & & \\
\hline
\end{tabular}


Table 3 Respondents' willingness to participate in compassionate community education (CCE), compassionate community network (CCN) and palliative care education (PCE) and to provide palliative care (PC) $(n=159)$

\begin{tabular}{lll}
\hline Willingness to participate in or to provide & $\mathbf{N}$ & $\%$ \\
\hline CCE & 80 & 50.3 \\
CCN & 78 & 49.1 \\
PCE & 81 & 50.9 \\
PC services & 31 & 19.5 \\
\hline
\end{tabular}

services $(45.3 \%)$ and influenza vaccination $(42.1 \%)$; only $5.7 \%$ provided PC.

\section{Respondents' willingness to participate in CCE, CCN and PCE and to provide PC}

Exactly half of the respondents were willing to participate in CCE, $49.1 \%$ in CCN and 50.9\% in PCE. However, only $19.5 \%$ were willing to provide PC (table 3 ).

\section{Factors related to the willingness to participate in CCE, CCN and PCE and provide PC}

After adjusting for covariates, the following had significantly positive willingness to participate in CCE: respondents who were 40-59 years old (adjusted OR (aOR): 5.972, 95\% CI: 1.659 to 21.499), compared with the 20-39 year olds; men as compared with women (aOR: 9.071, 95\% CI: 1.634 to 50.352); married respondents as compared with those who were single (aOR: 0.143, 95\% CI: 0.031 to 0.648 ); nurses versus non-nurses (aOR: $3.244,95 \%$ CI: 1.027 to 10.253 ); those with a monthly income $\geq 60000$ New Taiwan Dollar (NTD) as compared with those with a monthly income $<59999$ (aOR: 9.320, 95\% CI: 1.393 to 62.367 ); and those who had received PCE in the past 3 years as compared with those who did not (aOR: 5.291, 95\% CI: 1.718 to 16.299). Regarding the willingness to participate in CCN, the following had significantly positive willingness: respondents who were 40-59 years old (aOR: 4.951, 95\% CI: 1.423 to 17.230) as compared with those who were 20-39 years old, men as compared with women (aOR: 9.853, 95\% CI: 1.739 to 55.835), nurses versus non-nurses (aOR: 3.159, 95\% CI: 1.003 to 9.951), those who had a monthly income $\geq 60000 \mathrm{NTD}$ as compared with those who had a monthly income $<59999$ (aOR: 8.817, 95\% CI: 1.365 to 56.962) and those who had received PCE in the past 3 years as compared with those who did not (aOR: 6.325, 95\% CI: 1.945 to 20.596). Regarding the willingness to participate in PCE, the following had significantly positive willingness: respondents who were $40-59$ years old (aOR: $6.374,95 \%$ CI: 1.727 to 23.526 ) as compared with 20-39 years old, men as compared with women (aOR: 5.948, 95\% CI: 1.181 to 29.963$)$, married respondents as compared with those who were single (aOR: 0.144, 95\% CI: 0.032 to 0.661 ), nurses as compared with other primary care clinic staff (aOR: 3.29, 95\% CI: 1.030 to 10.513 ), those who had a monthly income $\geq 60000$ NTD as compared with those who had an monthly income <59 999 (aOR: 11.603, 95\% CI: 1.659 to 81.172) and those who had received PCE in the past 3 years as compared with those who did not (aOR: $7.183,95 \%$ CI: 2.173 to 23.743 ). The factors significant with the willingness to provide PC were nursing staff and those who had received PCE in the past 3 years (aOR: 6.047, 95\% CI: 1.125 to 32.809 ; aOR: $3.936,95 \%$ CI: 1.275 to 12.148 ). From the results of logistic regression models, we found that physicians were significantly less willing than other staff to participate in CCE, CCN and PCE (table 4).

\section{QUALITATIVE RESULTS}

In total, 158 participants responded to the open questions. Using qualitative content analysis, four main categories were classified for participating in CCE and CCN under each of the four heads.

\section{Professionalism, continuing medical education and providing services}

This category contained the major descriptions of respondents' willingness to participate in CCE, with $35(43.8 \%)$ responses. Some responses were: 'I want to get the certificate after receiving these education programs' (two physicians and five nurses), and 'I can provide professional services to people who need it' (10 physicians, five nurses, three administrative staff and two directors). They deemed this education capable of improving their professionalism, helping them to gain continuing medical education credits and provide services to those in need.

\section{Interests}

Some respondents said, 'I would like to join these education programs because I am interested in these classes' (nine physicians, eight nurses, one pharmacist and two administrative staff), but some others said, 'I am not interested in these classes' (13 physicians, two nurses, one pharmacist, nine administrative staff and two directors) and 'I am interested in join the CCN, because people in our society is getting older and they need support' (19 physicians).

\section{Administrative, manpower concerns and time}

Some responses were as follows: 'I would like to join CCE and CCN, if I have time' (16 physicians, five nurses and three administrative staff), and 'My work is busy and I do not have time to participate the CCE' (eight physicians, seven nurses and seven administrative staff). One physician said, 'Due to lack of manpower, I can't join CCE or CCN'. One nurse and one administrative staff said, 'It depends on the director's decision to join the CGN'.

Age and motivation

Seventeen respondents (21.5\%) stated that 'I am prepared to retire and lacked the motivation to 


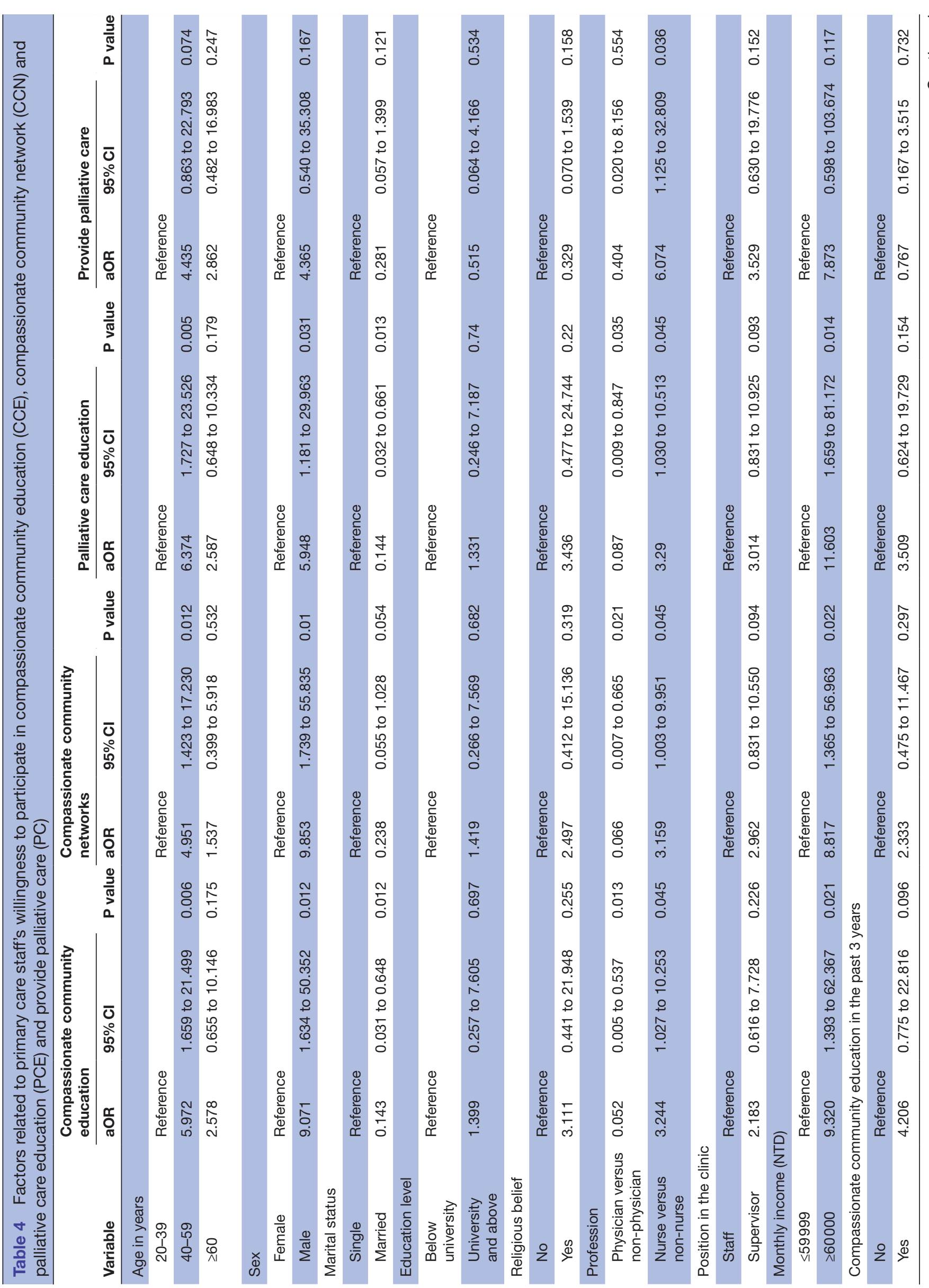


participate in CCE and CCN' (15 physicians, one nurse and one administrative staff).

Four main categories were classified for respondents' willingness to participate in PCE.

\section{Professionalism, continuing medical education, capability and providing services}

Thirty-four $(42.0 \%)$ respondents wanted to participate in PCE to improve their professionalism and capabilities, receive continuing education credits and provide services to those in need. Respondents expressed, 'I am a medical professional and it is my responsibility to provide healthcare to those who in need of it' (14 physicians, 16 nurses, three pharmacists and one physiotherapist) and 'I need to receive continual medical education to update my medical knowledge and to improve my capability to care patients and provide healthcare services to patients in the community' (two physicians and five nurses).

\section{Interests}

While 20 respondents $(24.7 \%)$ were interested in participating in PCE, $34(44.2 \%)$ were uninterested. Some participants expressed, 'There are more and more people will need palliative care and I am interested in this education' (nine physicians, eight nurses, one pharmacist and two administrative staff), but some others said, 'I think the medical professionals in the tertiary hospitals are more capable of providing palliative care and I am not interested in this education' (17 physicians, five nurses, one pharmacist and nine administrative staff).

\section{Administrative, manpower concerns and time}

Similarly, $25(30.9 \%)$ respondents wanted to participate in PCE if they had time, while 48 (37.8\%) were unwilling because of administrative issues and lack of manpower. 'Due to administrative limitations and there is a lack of manpower in my clinic, so I do not have time to join these education programs', said nine physicians, nine nurses and four administrative staff.

\section{Age and motivation}

Sixteen (20.8\%) respondents were unwilling to participate in PCE because of age: 'I am old and prepared to retire and do not have the motivation to join these education programs' (14 physicians, one nurse and one administrative staff).

Four main categories were classified for respondents' willingness to provide palliative care.

\section{Professionalism and capability}

Among those willing to provide PC, 11 (35.5\%) wanted to because of professionalism and responsibility, while $14(11.0 \%)$ were unwilling because they were incapable or their profession did not allow it. Some participants expressed the following: 'I am a medical professional and it is my responsibility to provide healthcare to those who in need of it' (nine physicians and two nurses), and others said, 'I think the medical professionals in the tertiary 
hospitals are more capable of providing palliative care' (six physicians, two nurses and seven administrative staff).

\section{Interests}

Fifty respondents $(39.4 \%)$ were uninterested in proving PC (21 physicians, 15 nurses, 2 pharmacists and 12 administrative staff).

\section{Administrative, manpower concerns and time}

Twenty-seven (21.3\%) respondents expressed inability to provide PC due to administrative concerns; 10 (7.9\%) blamed a lack of manpower, while $11(8.7 \%)$ cited time constraints: 'Due to administrative limitations and lack of manpower in my clinic, I do not have time to provide PC to patients in their home', said 25 physicians, 17 nurses and 6 administrative staff.

\section{Age and motivation}

Fourteen (11.0\%) were prepared to retire and unwilling to provide this care; five of them blamed a lack of motivation. These were 13 physicians and one administrative staff.

\section{DISCUSSION}

There were several important findings from this study. First, about half of the respondents were willing to participate in CCE, CCN and PCE but only $19.5 \%$ to provide PC. Second, factors significantly associated with participation in CCE and PCE were similar, which included being 40-59 years old, male, married and nurses; a relatively high monthly income; and received PCE in the past 3 years. Third, factors significantly associated with the willingness to participate in CCN included being 40-59 years old, male and nurses; a relatively high monthly income; and received PCE in the past 3 years. Fourth, factors significantly related to the willingness to provide PC included being nurses and having received PCE in the past 3 years. Fifth, physicians were significantly less willing to participate in CCE, CCN and PCE.

Moreover, having received PCE in the past 3 years was significantly associated with respondents' willingness to participate in CCN and provide PC. To the best of our knowledge, no previous studies have focused on factors associated with primary care staff members' willingness to participate in CCN, but some have considered professionals' willingness to provide PC. Willingness to participate in PCE might represent a need or interest and allow professionals to increase their knowledge or skills within the CCN and then provide PC. After this upgrade, professionals may become more confident in these activities. In this context, a previous study showed that PCE is independently associated with the agreement on GPs' roles in PC. ${ }^{13}$ Meanwhile, another study found that community physicians' beliefs and experiences in PC, rather than their knowledge, were related to their willingness to provide PC for patients terminal cancer. ${ }^{14}$ Further, another study found that PC knowledge was associated with community nurses' willingness to provide PC in rural communities. ${ }^{15}$ Additionally, community pharmacists could play roles in community PC through medication reviews to improve patients' medication management and decrease errors, and their involvement could also improve the medication-related knowledge and skills of care team members. ${ }^{16}{ }^{17}$ However, continuing professional development in PC, particularly in communication skills and managing emotions with patients, is important to facilitate their willingness to participate in the care. ${ }^{1621}$ Thus, education has been noted to be an important factor related to reducing barriers to providing PC. ${ }^{22}$ Further study should be conducted to explore the mechanisms of these associations.

Compared with other staff, nurses in primary care clinics had a significantly higher willingness to participate in CCE, CCN and PCE and provide PC. A previous study showed that a caring nature is a key factor for nurses, and this profession also allows them to help people. ${ }^{23}$ The characteristic traits of persistence, self-directedness, cooperativeness and self-transcendence are the possible reasons associated with nurses' willingness to participate in such education and provide support or PC. ${ }^{24}$ Meanwhile, another study found that PC nurses were extraverted, empathic, trusting, open, expressive, insightful and group-oriented. ${ }^{25}$ Further study could be conducted to explore the personalities of primary care nurses willing to participate in CCN.

Physicians were significantly less willing than other primary care staff to participate in CCE, CCN and PCE, but there was no significant difference in their willingness to provide PC. The finding is different from that of a recent qualitative study that evaluated GP's perceptions of compassionate communities in the UK; it found GPs recognised that wider community involvement in caring for PC patients is important. ${ }^{26}$ However, most of the physicians were unfamiliar with the compassionate community approach. In our study, $52(65.8 \%)$ primary care physicians had heard about compassionate communities, and about $70 \%$ were willing to participate in CCE and CCN, yet overall willingness was low. Qualitative results find that most of them considered receiving continuing education and participating in compassionate communities interesting and providing support or care to people part of their professionalism and responsibilities. However, their general willingness stemmed from the following reasons: they had prepared for retirement (age), and they lacked interest and necessary manpower to provide such support. A previous study had disclosed practise size, years of experience as a GP and receiving PCE as factors relating to GPs' willingness to provide community PC. ${ }^{16}$ Another study found that community physicians' perceptions of barriers and threats to providing PC included medical failure, lacking hope for a cure, inability to control difficult symptoms and face the dying process and distress. ${ }^{17}$ To facilitate primary care physicians' involvement in CCN and providing PC, policymakers should pay more attention to removing these barriers and concerns. 
This study has several strengths. First, this is the first study to explore primary care staffs' willingness to participate in CCE, CCN and PCE and to provide PC in Asia. Second, we collected quantitative and qualitative data to improve the findings' validity. Third, the respondents included physicians, nurses and administrative staff, who are the main staff in primary care settings in Taiwan, and given the acceptable response rate, the results of this study could have acceptable representativeness for overall primary care staff's willingness in the study area. However, several limitations should be considered when interpreting the results. First, because of the crosssectional study design, we were unable to show the causal relationship between factors associated with respondents' willingness and study outcomes. Second, although we adjusted for covariates in the logistic regression models, some unmeasured confounding factors may not have been included. Third, the questionnaire contained four open questions for respondents to freely express their reasons for participation, and in-depth interviews should be considered in further research to elaborate on these answers for better results.

\section{CONCLUSIONS}

About $50 \%$ of primary care staff are willing to participate in CCE, CCN and PE, but only $19.5 \%$ is willing to provide PC. Compared with other staff, nurses were significantly more willing to participate in CCE, CCN and PE and provide $\mathrm{PC}$, but physicians were significantly not willing to participate in CCE, CCN and PE. Capability, administrative and manpower concerns, time, age and motivation were the main barriers to their engagement. Adequate PCE is significantly related to their willingness to participate. Implementing the compassionate community model in Taiwan is possible by recruiting primary care staff for providing CCE and PCE. In this study, adequate PCE is significantly related to the staff's engagement; therefore, topics on PC could be included in continuing medical education. Policymakers should pay more attention to barriers, including capability, administrative and manpower concerns, time, age and motivation, which prevent participation and care provision.

\section{Author affiliations \\ ${ }^{1}$ Department of Family Medicine, Taipei Veterans General Hospital, Taipei, Taiwan ${ }^{2}$ Faculty of Medicine, School of Medicine, National Yang Ming Chiao Tung University, Taipei, Taiwan \\ ${ }^{3}$ Institute of Science, Technology and Society and Institute of Public Health, National Yang Ming Chiao Tung University, Taipei, Taiwan \\ ${ }^{4}$ Department of Radiology, Taipei Veterans General Hospital, Taipei, Taiwan \\ ${ }^{5}$ Institute of Hospital and Health Care Administration, National Yang Ming Chiao Tung University, Taipei, Taiwan}

Acknowledgements The authors thank all respondents for their participation and the Taipei Veterans General Hospital for the administrative support.

Contributors H-TC conceived of the original idea, carried out the study, contributed to data collection and data analysis, interpreted the results, drafted the article and revised the manuscript. M-HL, W-HK and C-KC contributed to the preparation of the dataset, interpreted the results, drafted the article and revised the manuscript. T-JC and S-JH contributed to the interpretation of results and commented on drafts of the article and revised the manuscript.

Funding $\mathrm{H}-\mathrm{TC}$ received a grant from the Taiwan Ministry of Science and Technology (MOST 108-2314-B-075-036).

Competing interests None declared.

Patient and public involvement Patients and/or the public were not involved in the design, conduct, reporting or dissemination plans of this research.

Patient consent for publication Not required.

Provenance and peer review Not commissioned; externally peer reviewed. Data availability statement Data are available upon reasonable request.

Open access This is an open access article distributed in accordance with the Creative Commons Attribution Non Commercial (CC BY-NC 4.0) license, which permits others to distribute, remix, adapt, build upon this work non-commercially, and license their derivative works on different terms, provided the original work is properly cited, appropriate credit is given, any changes made indicated, and the use is non-commercial. See: http://creativecommons.org/licenses/by-nc/4.0/.

ORCID iD

Hsiao-Ting Chang http://orcid.org/0000-0003-0421-8499

\section{REFERENCES}

1 Kellehear A. Health-Promoting palliative care: developing a social model for practice. Mortality 1999;4:75-82.

2 Wegleitner K, Heimerl K, Kellehear A. Compassionate communities: case studies from Britain and Europe. 1st ed. London and New York: Routledge, 2016

3 Fook J, Kellehear A. Using critical reflection to support health promotion goals in palliative care. J Palliat Care 2010;26:295-302.

4 Haraldsdottir E, Murray S, Clark P. Health-Promoting palliative care arrives in Scotland. Eur J Palliat Care 2010;17:130-2.

5 Abel J, Bowra J, Walter T, et al. Compassionate community networks: supporting home dying. BMJ Support Palliat Care 2011;1:129-33.

6 Greene A, Aranda S, Tieman JJ, et al. Can assessing caregiver needs and activating community networks improve caregiverdefined outcomes? A single-blind, quasi-experimental pilot study: community facilitator pilot. Palliat Med 2012;26:917-23.

7 Gómez-Batiste X, Mateu S, Serra-Jofre S, et al. Compassionate communities: design and preliminary results of the experience of Vic (Barcelona, Spain) caring City. Ann Palliat Med 2018;7:S32-41.

8 Librada Flores S, Herrera Molina E, Boceta Osuna J, et al. All with you: a new method for developing compassionate communitiesexperiences in Spain and Latin-America. Ann Palliat Med 2018;7:S15-31.

9 Tompkins B. Compassionate communities in Canada: it is everyone's responsibility. Ann Palliat Med 2018;7:S118-29.

10 Huang S-J, Wang SS-C, Lee OK-S, et al. 2016 Taipei Declaration for prevention of suffering. J Palliat Med 2016;19:1243-4.

11 Huang S-J, Huang C-Y, Woung L-C, et al. The 2017 Taipei Declaration for health-promoting palliative care. J Palliat Med 2018;21:581-2.

12 Huang S-J, Huang C-Y, Woung L-C, et al. The 2018 Taipei Declaration for ultimate integration of palliative care. $J$ Palliat Med 2019;22:476-7

13 Burt J, Shipman C, White P, et al. Roles, service knowledge and priorities in the provision of palliative care: a postal survey of London GPs. Palliat Med 2006;20:487-92.

14 Peng J-K, Chiu T-Y, Hu W-Y, et al. What influences the willingness of community physicians to provide palliative care for patients with terminal cancer? Evidence from a nationwide survey. Jpn J Clin Oncol 2013;43:278-85.

15 Hu W-Y, Chiu T-Y, Dai Y-T, et al. Nurses' willingness and the predictors of willingness to provide palliative care in rural communities of Taiwan. J Pain Symptom Manage 2003;26:760-8.

16 O'Connor M, Fisher C, French L, et al. Exploring the community pharmacist's role in palliative care: focusing on the person not just the prescription. Patient Educ Couns 2011;83:458-64.

17 Hussainy SY, Box M, Scholes S. Piloting the role of a pharmacist in a community palliative care multidisciplinary team: an Australian experience. BMC Palliat Care 2011;10:16.

18 Morgan DL. Qualitative content analysis: a guide to paths not taken. Qual Health Res 1993;3:112-21. 
19 Hsieh H-F, Shannon SE. Three approaches to qualitative content analysis. Qual Health Res 2005;15:1277-88.

20 Miyashita J, Kohno A, Cheng S-Y, et al. Patients' preferences and factors influencing initial advance care planning discussions' timing: a cross-cultural mixed-methods study. Palliat Med 2020;34:906-16.

21 Ise Y, Morita T, Maehori N, et al. Role of the community pharmacy in palliative care: a nationwide survey in Japan. $J$ Palliat Med 2010;13:733-7.

22 Centeno C, Garralda E, Carrasco JM, et al. The palliative care challenge: analysis of barriers and opportunities to integrate palliative care in Europe in the view of national associations. $J$ Palliat Med 2017;20:1195-204.
23 Eley D, Eley R, Bertello M, et al. Why did I become a nurse? Personality traits and reasons for entering nursing. J Adv Nurs 2012;68:1546-55.

24 Eley D, Eley R, Young L, et al. Exploring temperament and character traits in nurses and nursing students in a large regional area of Australia. J Clin Nurs 2011;20:563-70.

25 Gambles M, Wilkinson SM, Dissanayake C. What are you like?: a personality profile of cancer and palliative care nurses in the United Kingdom. Cancer Nurs 2003;26:97-104.

26 Abbey E, Craig C, Mayland CR. General practitioners' perceptions of compassionate communities: a qualitative study. BMC Palliat Care 2020;19:97 